\title{
Building Virtual Collaborative Research Community Using Knowledge Management Approach
}

\section{Ju-Ling Shih}

Department of Information and Learning Technology, National University of Tainan, No. 33, Sec. 2, Shu-Lin St., Tainan, Taiwan,

R.O.C. 70005

E-mail: juling@mail.nutn.edu.tw

\section{Jussi Nuutinen}

School of Computing, Joensuu Campus, University of Eastern Finland, Finland, P.O. Box 111, FI-80101, Joensuu, Finland

E-mail: jussian@cs.joensuu.fi

\section{Gwo-Jen Hwang}

Graduate Institute of Digital Learning and Education, National Taiwan University of Science and Technology 43, Sec.4, Keelung Rd., Taipei, 106, Taiwan

E-mail: gjhwang.academic@gmail.com

\section{Nian-Shing Chen*}

Department of Information Management, National Sun Yat-Sen University, No. 70, Lien-Hai Rd., Kaohsiung, Taiwan, 80424

E-mail:nschen@mis.nsysu.edu.tw

*Corresponding author

\begin{abstract}
Many online communities nowadays are emphasized more on peer interactions and information sharing among members; very few online communities are built with knowledge management in nature supported by knowledge management system (KMS). This study aims to present a community of practice on how to effectively adopt a knowledge management system (KMS) to neutralize a cyber collaborative learning community for a research lab in a higher education setting. A longitudinal case for 7 years was used to analyze the retention and extension of participants' community of practice experiences. Interviews were conducted for the comparison between experiences and theories. It was found that the transformations of tacit and explicit knowledge are in accordance with the framework of Nonaka's model of knowledge management from which we elicit the strategies and suggestions to the adoption and implementation of virtual collaborative research community supported by KMS.
\end{abstract}

Keywords: Knowledge Management System, Online Community, Collaborative Learning Community, Longitudinal Case Study. 
Biographical notes: Ju-Ling Shih is currently an Associate Professor of the Department of Information and Learning Technology in National University of Tainan, Taiwan. She earned her Ed.D. in Communication and Education from Teachers College, Columbia University, specializing in communication and instructional technology. Her research interests include instructional design and qualitative research in digital learning, digital games, mobile learning, and technology-mediated education in various levels and fields.

Jussi Nuutinen is currently a software designer at Honkalampi Foundation. He received his Ph.D. degree in Computer Science in 2009 from the University of Joensuu. He was part of the educational technology research group and is still active in that group. His research interest are computer supported collaborative learning, communication and educational technology in general.

Gwo-Jen Hwang is currently a Chair Professor in the Graduate Institute of Digital Learning and Education at National Taiwan University of Science and Technology. In 1991, Dr. Hwang received his Ph.D. degree in Computer Science and Information Engineering from National Chiao Tung University in Taiwan. His research interests include mobile and ubiquitous learning, computer-assisted testing, expert systems and knowledge engineering. Dr. Hwang has published more than 330 academic papers, including 118 papers in such professional journals as Computers \& Education, Educational Technology \& Society, British Journal of Educational Technology, Innovations in Education and Teaching International, and The Electronic Libraries among others. Owing to the good reputation in academic research and innovative inventions of e-learning, in 2007, he received the annual Most Outstanding Researcher Award from the National Science Council in Taiwan.

Nian-Shing Chen is a distinguished Professor at the Department of Information Management in the National Sun Yat-sen University, Taiwan. He has published over 300 papers in international referred journals, conferences and book chapters. He is also the author of three books with one textbook entitled "eLearning Theory \& Practice". Prof. Chen received the distinguished research award from the National Science Council, Taiwan in 2008. His current research interests include assessing e-Learning course performance; online synchronous teaching \& learning; mobile \& ubiquitous learning. Professor Chen is a member of IEEE, ACM and the Chair for Expert Seminars and Web-based Tutorials, the IEEE Technical Committee on Learning Technology (http://ttf.ieee.org/). He is a Co-Editor of the SSCI indexed Journal of Educational Technology \& Society.

\section{Introduction}

Knowledge management concept has gone through major evolution since the prevalence of computers and the Internet. The Internet has made possible the interaction between distant collaborators. With appropriate technologies, informal communication and formal idea exchange can be transformed into collaborative knowledge creation. Collaborative activities such as sharing data and knowledge as well as having discussions around the content create valuable asset for research groups. Many online communities nowadays are more emphasized on peer interactions and information sharing among members; very few online communities are built with knowledge management in nature supported by knowledge management system (KMS) (Su, Zhang, \& Hashemi, 2007; Wang, Rabsch, Kling, Peiya, \& Pearson, 2007). The benefits of adopting knowledge management system 
into research arena include the possibilities to represent the data in various formats, and the possibility to manage and scaffold tasks and procedures (Hoadley \& Killner, 2005). Such community of practice is enacted in the virtual environment. Hoadley and Killner (2005) introduced that with knowledge management system (KMS), technology has realized the concept of virtual community of practice. In order to better facilicating individual knowledge construction, KMS provides such scaffolding framework with asynchronous and synchronous functionalities.

Since multi-disciplinary research is getting more and more important, how to better facilitate collaborations among researchers across the globe is becoming an important issue for good multi-disciplinary research outcome (Diaper \& Sanger, 2006; Gupta \& Karisiddappa, 1998), this motivates us to introduce the case with 7-year adoption for the researchers to experience how to deploy collaborative research supported by KMS. We proposed a framework of technology enhanced collaborative research as the guidelines for a research group adopting KMS to neutralize a cyber collaborative learning community for a research lab.

This paper first introduces the functionalities of the developed KMS and how they were carried out to enhance online research community. We then analyzed the data logged in the KMS and conducted interviews with the members for in-depth understanding about the process of the formation and creation of an online collaborative research community. Finally, we discussed the benefits and drawbacks of the developed KMS and suggested some future research issues.

\section{Literature Review}

In management research, knowledge is generally categorized into explicit knowledge and tacit knowledge. Nonaka and Takeuchi (1995) coined the terms as the two main types of human knowledge and articulated it as the Model of Knowledge Creation and Transformation. The concept is further explored that explicit knowledge is the one that can be encoded and stored, easier to transmitted (Krogh, 1998), and tacit knowledge is normally developed from action and experience, and shared through highly interactive communication (Zack, 1999).

Nonaka and Takeuchi (1995) said that the key to knowledge creation lies in the way it is mobilized and converted through technology. The Model of Knowledge Creation and Transformation unfolds according to spiral morphology through process of socialization, externalization, internalization, and combination (see Table 1).

Davenport and Prusak (1998) also mentioned that knowledge is a fluid synthesis that the experience, value, and verbal information with expert's unique insight can offer structure for the evaluation, synthesis, and information for generating new experiences. Therefore, Krogh (1998) thinks that knowledge management is not only to build information storage, local area network, expert system, or organization routines, but to emphasize on the source of creation, which is the tacit knowledge.

Knowledge production (creation) refers to the accumulation of intellectual capital. Users learn by doing and creating. The Web is arguably the most successful open information distribution mechanism in existence (Karger \& Quan, 2005). These technologies try to address a similar question, namely, how to enable people to quickly and easily publish their knowledge so that it can be effectively and securely shared with other members of the community. Knowledge consumption (transfer), on the other hand, 
is done through social networking mechanism, that community members can learn with experts and the scaffolds they provide (Wagner \& Bolloju, 2005).

Table 1. Nonaka's Model of Knowledge Creation and Transformation

\begin{tabular}{|c|c|c|}
\hline From To & Tacit Knowledge & Explicit Knowledge \\
\hline $\begin{array}{l}\text { Tacit } \\
\text { Knowledge }\end{array}$ & $\begin{array}{l}\text { Socialization: Sympathized } \\
\text { knowledge. } \\
\text { Share experiences to create tacit } \\
\text { knowledge. Takes place between } \\
\text { people in meetings or in team } \\
\text { discussions. }\end{array}$ & $\begin{array}{l}\text { Externalization: Conceptual knowledge. } \\
\text { Articulate tacit knowledge explicitly, } \\
\text { metaphors, concepts, hypotheses, models, } \\
\text { writing. Articulation among people } \\
\text { through dialog (e.g., brainstorming). }\end{array}$ \\
\hline $\begin{array}{l}\text { Explicit } \\
\text { Knowledge }\end{array}$ & $\begin{array}{l}\text { Internalization: Operational } \\
\text { knowledge. } \\
\text { Learning by doing, to develop } \\
\text { shared mental models and } \\
\text { technical know-how. This } \\
\text { implies taking explicit } \\
\text { knowledge (e.g., a report) and } \\
\text { deducing new ideas or taking } \\
\text { constructive action. One } \\
\text { significant goal of knowledge } \\
\text { management is to create } \\
\text { technology to help the users to } \\
\text { derive tacit knowledge from } \\
\text { explicit knowledge. }\end{array}$ & $\begin{array}{l}\text { Combination: Systemic knowledge. } \\
\text { Manipulating explicit knowledge by } \\
\text { sorting, adding, combining, etc. This } \\
\text { transformation phase can be best } \\
\text { supported by technology. Explicit } \\
\text { knowledge can be easily captured and } \\
\text { then distributed/transmitted to worldwide } \\
\text { audience. }\end{array}$ \\
\hline
\end{tabular}

Zack (1999) said that the process of knowledge refinement is the process to create and disseminate the knowledge in the system, which include retrieval, refinement, indexing, distribution, and representation. Rosenberg (2001) proposed the knowledge management pyramid model to include three layers. The lowest is the document management for the support of information distribution. The second layer is the information creation, sharing, and management where people actually give information to system, create new content, and enrich knowledge database for online retrievals. The third layer is the entrepreneurial wisdom which to express the organizational know-how. So, Jackson (2000) expressed that knowledge processes are multidimensional, provide value and are not the same thing as 'data' or 'information.' He defined knowledge management within the context of information systems to have functions of managing the gathering, organizing, refining, analyzing, and disseminating of knowledge in all of its forms. It supports organizational functions while addressing the needs of the individual within a purposeful context.

Knowledge management (organization) is to use hierarchical KM structure to enhance learning with systematic instruction and progress. Three technologies including discussion forums, wikis, and weblogs, are conversational technologies that reflect much of the knowledge creation and sharing is carried out through a process of discussion with questions and answers (discussion forum), collaborative editing (wikis), or through a process of storytelling (weblogs) (Wagner \& Bolloju, 2005). Conversations, whether in 
discussion forums or other media have been recognized as a useful medium for knowledge exchange and extraction (Nishida, 2002). Consequently, conversational knowledge management should yield benefits at numerous stages of the knowledge management process beginning with knowledge creation and ending with knowledge use and refinement (Wagner \& Bolloju, 2005). These tools need to be able to represent information and knowledge in plain text, paired with the ability to build relationships to other content in the repository. Its characteristics include supporting the collaboration of people, supporting forms or knowledge organization, such as threading or hyperlinking, and containing mechanisms for knowledge protection in a shared environment (security) (Wagner \& Bolloju, 2005).

\section{Methods}

In order to support a cyber collaborative learning community for a research lab, a KMS has been developed and deployed since 2000 to support Virtual Collaborative Research Community (VCRC) at the E-Learning and Knowledge Management Research Center in the National Sun Yat-Sen University where a Professor leads a group of graduates that consists of $3 \mathrm{PhD}$ students and 10 master students.

The framework of KMS is like a social network map that guides participants to understand the relationships between participants' roles and their activities (Wasserman $\&$ Faust, 1994). The functionalities of the developed KMS and the learning activities conducted in this research are mapped in Table 2.

Table 2. Functionalities of the developed KMS and conducted learning activities

\begin{tabular}{|c|c|c|}
\hline & Individual & Collaborative \\
\hline Asynchronous & $\begin{array}{l}\text { 1. Threaded Discussion Forum. } \\
\text { - Record research note, } \\
\text { documents, progress reports, } \\
\text { and thoughts. } \\
\text { - Organize and build personal } \\
\text { knowledge. } \\
\text { - Allow comments from other } \\
\text { members. } \\
\text { 2. Email List } \\
\text { 3. Document Exchange }\end{array}$ & $\begin{array}{l}\text { 1. Threaded Discussion Forum } \\
\text { - Store shared information. } \\
\text { - Select and build group } \\
\text { knowledge. } \\
\text { - Discuss issues, problems } \\
\text { related to common } \\
\text { interests. } \\
\text { 2. Public Area } \\
\text { - Social events }\end{array}$ \\
\hline Synchronous & Not applicable & $\begin{array}{l}\text { 1. Videoconference, electronic } \\
\text { white board } \\
\text { - Online meeting: research } \\
\text { seminars and progress meetings. } \\
\text { - Automatic recording of the } \\
\text { meetings }\end{array}$ \\
\hline
\end{tabular}

\subsection{Individual Asynchronous Functions}

The KMS is a place to document one's learning experience. It provides each novice researcher privileges to manage a threaded-view forum as their personal research portfolio area (see Figure 1). The knowledge construction is generally displayed by the presentation style of hierarchical structure and it is efficient for knowledge reuse (Kuo \& $\mathrm{Chu}$, 2007). One can then post either web-based documents or multimedia-based 
documents. On the other hand, a personal blog enables one to create the blog with supported HTML language.

Generally, this provides a shared place for the learners to record what they had learned in the research training process and write research progress notes. Research training activities, like thesis construction, research paper review, and research publication can also be recorded in this area. The advantages include that 1) students produce a "learning diary" of their progress so they can easily reflect on their own progress and find their past records; 2) the supervisor is able to follow the progress of each student; 3 ) other students are able to know what other are doing and how they are progressing; and 4) novice students can read through older students research areas to learn from good practices and avoid mal-practices.

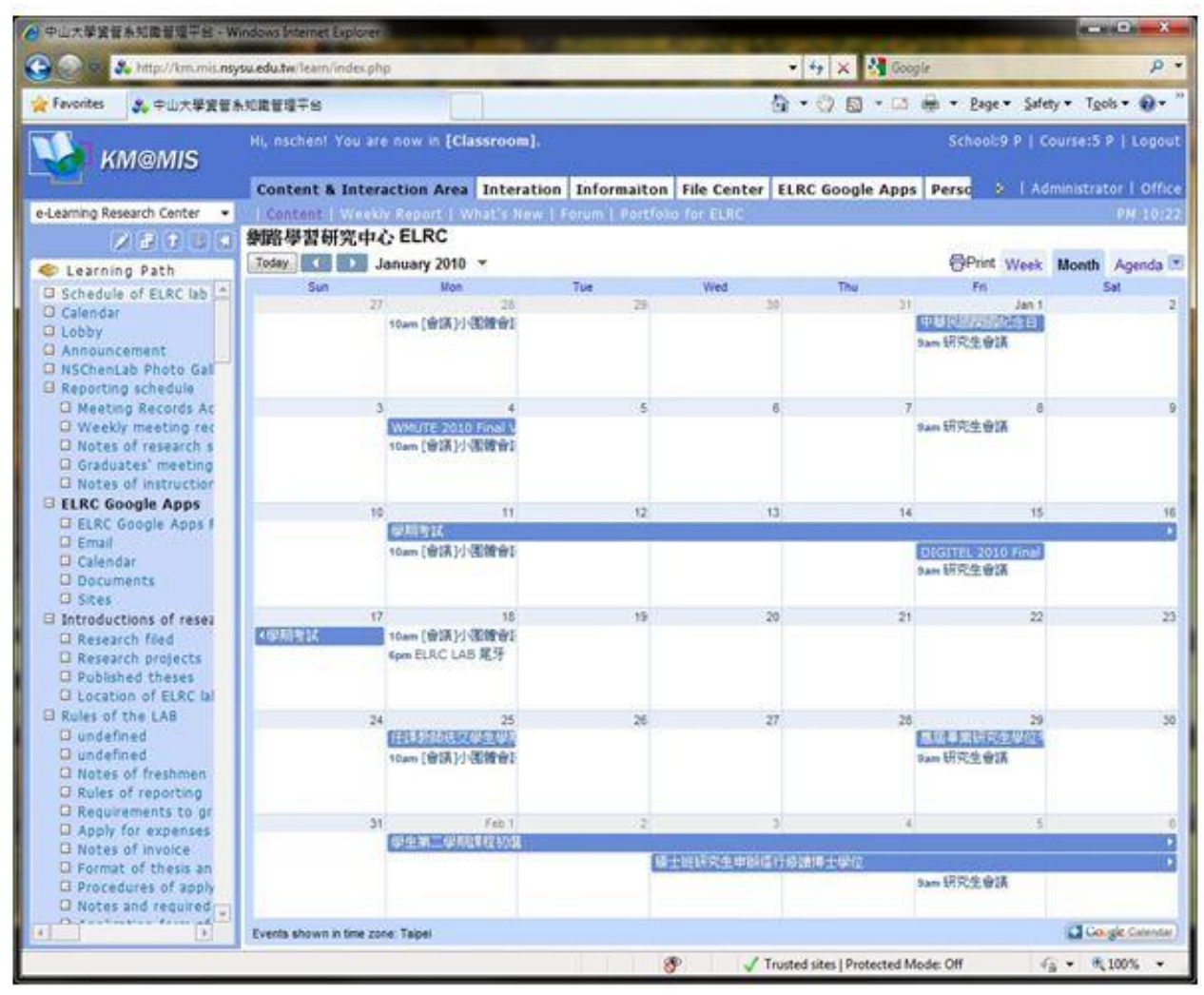

Figure 1. The Interface of VCRC Knowledge Management System

\subsection{Collaborative Asynchronous Functions}

In the collaborative tasks, the training process is team-based which composed of a senior researcher, a junior researcher, and a master student. And technology enables a research group to construct a virtual community of practices using this shared place to document and accumulate group learning experience and eventually become the basis for knowledge construction. Nonaka and Takeuchi (1995) mentioned that knowledge construction is a action-oriented process and subjectively to make tacit knowledge explicit and finally tacit, which is what makes a community knowledge valuable. 
Knowledge would need modification and be managed for best practice of guidance of the research group (Gover \& Davenport, 2001). The KMS was also designed that a privileged manager can change the knowledge structure and the contents after a resolution in the research seminar to fit the group need (see Figure 2). It is the selection and reorganization process of the items generated on collaborative process.

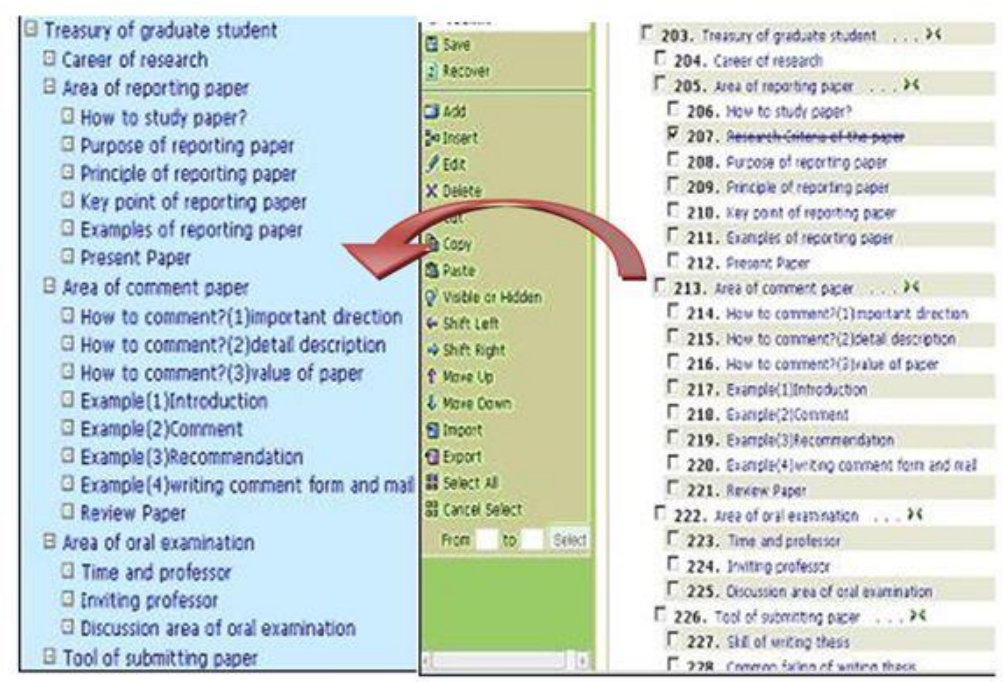

Figure 2. A modifiable knowledge construction of the hierarchical structure

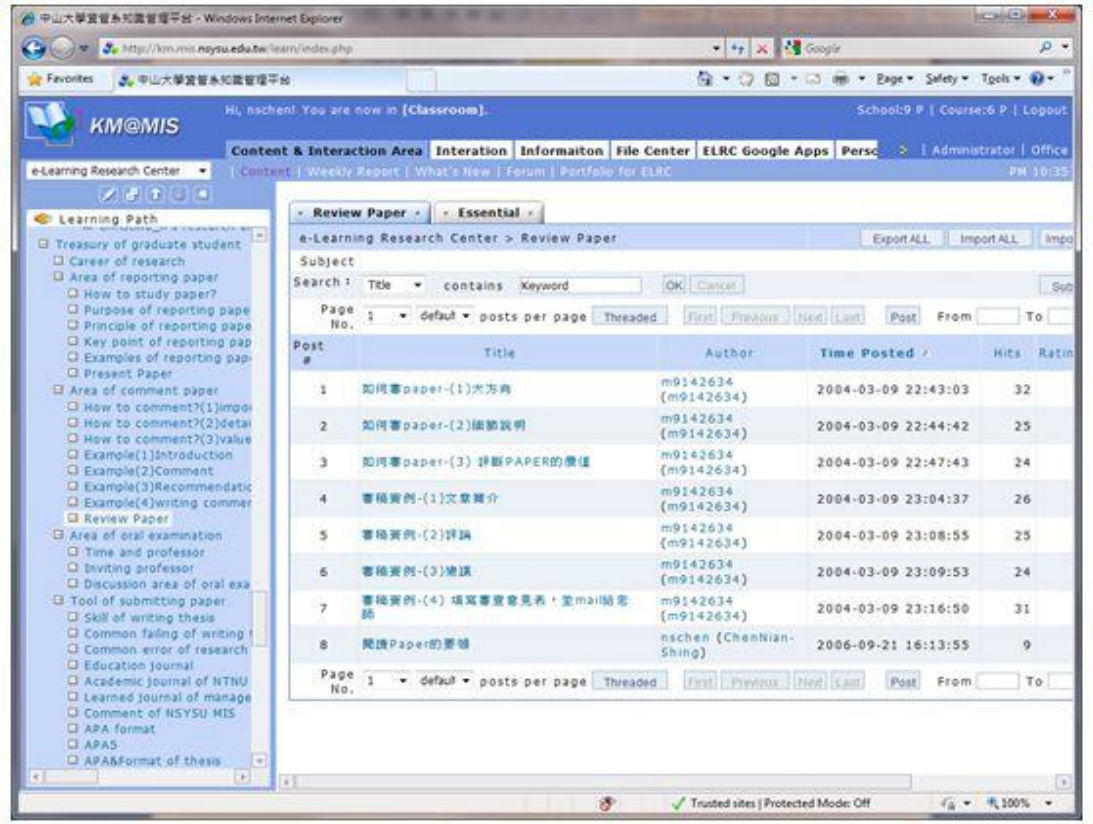

Figure 3. Papers review records shared as group examples 
With KMS, past experience on research training activities like research paper review, research publications, and thesis construction can be easily referred to examples from the online record (see Figure 3). A novice student L said to his peer M: "Thanks for sharing your papers review reports and I have realized that my review report is too naïve. I will try to learn from your examples to improve my paper reviewing skills."

\subsection{Collaborative Synchronous Functions}

An online synchronous communication tool has been used to create synchronous cyber offices for supporting the research team to work without time and geographic constraints. With this kind of synchronous cyber office, the supervisor managed to conduct weekly research seminars between Taiwan and Australia for several years (see Figure 4).

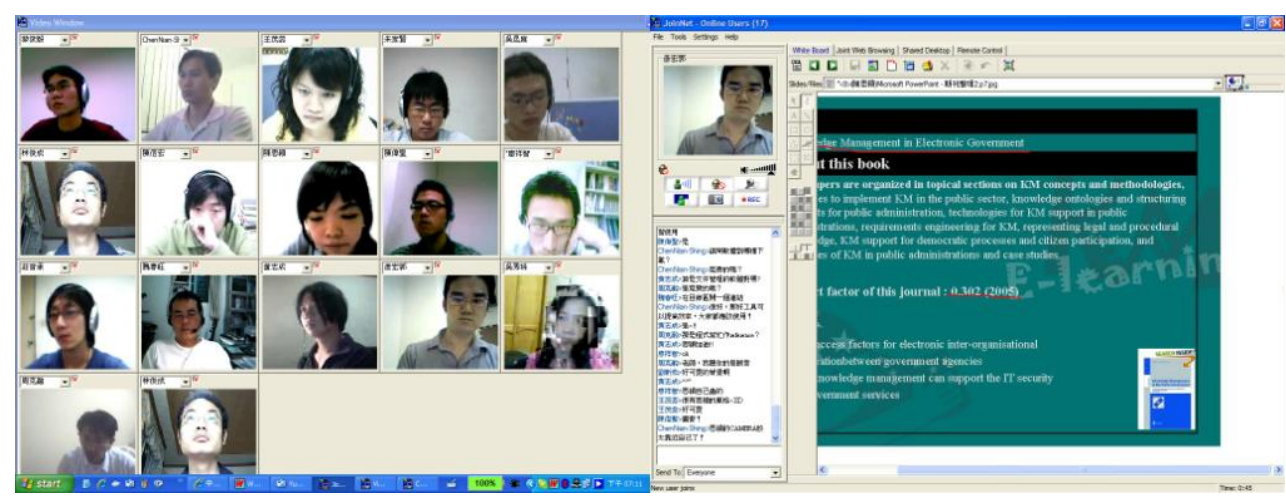

Figure 4. Online live research seminar using the synchronous cyber office

Synchronous cyber offices also support team discussion with functions such as electronic white-board, multiple video communications, and a share desktop (see Figure 4). It is used in many research training activities, like regular weekly research seminars, small group meetings and appointment discussions. The system can automatically record meetings for review and introspection later on.

In order to document the activities on the system, the KMS keeps all data for the past seven years. In this research, system logs are retrieved for analyzing and demonstrating the functionalities and effectiveness of the KMS. The statistics are presented below to show the growth of the usage and its related KM patterns. Due to the distant locations between users and researchers, instead of conducting individual interviews, open-ended questionnaire is distributed to 12 current and graduated members of VCRC (anonymous as Student A to L), who are in various school years and degree levels, to receive user feedbacks and explore the user experience with the system. Questionnaire to users covers a few aspects, including the use of KMS functions, the benefits of KMS to learning and research, knowledge worth to be collected as group assets, strategies to maintain virtual community, and functions to be added for future development. Similar answers from all the students are grouped together, and are explained with theories for in-depth analysis in the next section with equivalent titles respectively. 


\section{Practice and Reflection Analysis}

\subsection{Activity statistics on KMS}

Using the system logs, we retrieve the approximate number of postings throughout the last seven years. The statistics are shown in Table 3 and Figure 5.

Table 3. Statistics of KMS from year 2001 to 2007

\begin{tabular}{|l|r|r|r|r|r|r|r|}
\hline & 2001 & 2002 & 2003 & 2004 & 2005 & 2006 & 2007 \\
\hline Number of students & 5 & 5 & 10 & 9 & 5 & 8 & 6 \\
\hline $\begin{array}{l}\text { Total postings in discussion } \\
\text { forum }\end{array}$ & 83 & 223 & 1250 & 1233 & 1012 & 1589 & 1560 \\
\hline Total resource items on KMS & 86 & 185 & 944 & 524 & 708 & 988 & 1136 \\
\hline $\begin{array}{l}\text { Ave items per student in their } \\
\text { own research area }\end{array}$ & 33.80 & 81.60 & 219.4 & 195.2 & 344.0 & 123.5 & 449.3 \\
\hline $\begin{array}{l}\text { Total number of synchronous } \\
\text { meetings }\end{array}$ & 16 & 34 & 53 & 86 & 117 & 111 & 217 \\
\hline
\end{tabular}

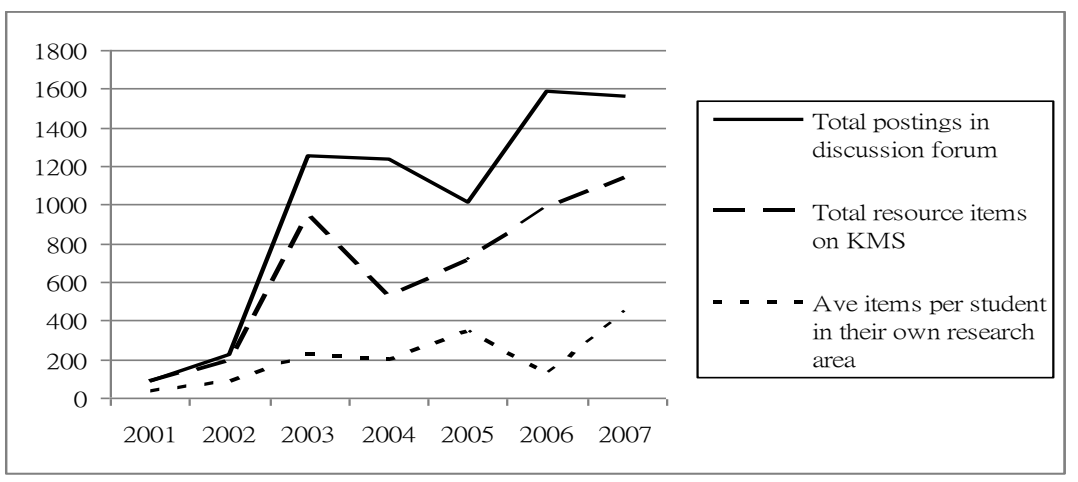

Figure 5. Graphical statistics of KMS activities from year 2001 to 2007

From the statistics, we find that the number of student remains within ten throughout the years, but the total number of synchronous meetings increased exponentially, from 16 in 2001 to 217 in 2007, with an average of almost one online meeting every working day in 2007. It signifies the culture of use has been established throughout the years. Also, it seems that the adaptation process took about three years to be stabilized and reached to a high point, and another three years to reach another peak. It shows a significant expansion to the information quantity which signifies the expansion of knowledge scope. However, after the year 2004, postings in discussion forum and average items per student in their own research area seemed to go to the opposite direction to each other. For example, in 2005, the total postings go down from 1233 to 
1012, and the average items per students go up from 195.2 to 344 . On the other hand, in 2006, the total postings go up from 1012 to 1589 , and the average items per students go down from 344 to 123.5. To follow the trend, numbers of the two items goes to the opposite direction as well. In other words, students seem to prefer either public postings or private documentation in different years instead of posting information in both places. This is an interesting topic for further exploration of the cause.

In addition, except a major downsizing year in 2004, the total resource items on KMS grow steadily throughout the years. That is due to the reason of the first peak in 2003 , the team became conscious of the fast growing postings on the KMS, and started to apply the knowledge management concept in 2004 that the team went through the synthesis, extraction, and reorganization period and started to maintain the KMS regularly to make individual information to become group knowledge. This is for the purpose of maintaining the quality of the collaborative knowledge and to increase the depth and value of social knowledge. It is also to transform the concept of knowledge repository to knowledge-based learning environment.

\subsection{Knowledge Flow of KMS Activities}

To analyze the KMS activities with Nonaka's Model of Knowledge Creation and Transformation, we can see the knowledge generally flow in 4 steps.

(1) Personal knowledge creation: Students work with their own documents to construct their own knowledge. It is done by sharing their personal knowledge with public on personal research portfolio area.

(2) Personal knowledge transformation to group knowledge: Students develop higher level knowledge to share with group on the public discussion forum. It is the process of making tacit knowledge into explicit.

(3) Group knowledge creation: In videoconferencing mechanisms, students share ideas and information. The group explicit knowledge is exchanged online.

(4) Group knowledge transformation to personal knowledge: The process is to extract the explicit knowledge into tacit where higher level of conceptual form of knowledge is created internally.

Although the KMS functions and learning activities happen all at the same time, but the flow of knowledge and the transformation happen in circular model as suggested above, which also matches Nonaka's model of knowledge transformation from socialization, externalization, combination, to internalization. Figure 2 shows the information interaction between personal area and public area, from which information is extracted from personal research documents and re-organized in the public domain as a list of permanent information. That signifies the transformation of individual knowledge to collaborative knowledge. Figure 6 shows how the group resources are listed which items are originally posted on personal research portfolio area (refers to Figure 1). The structural organization of the resources in the public area is transformed from the random listed items in the individual area that signified the interplay between personal (individual) knowledge and public (collaborative) knowledge.

From the structure and content of the group knowledge, concepts about how to generate research ideas, use APA formats, reflect on studies, write proposals, comment on papers, and provide suggestions, are experience and information that are most selected and categorized into public domain. At the same time, these know-hows of conducting research are declarative concepts that the detail explanation of the steps of research are often been classified into procedural knowledge thereafter for conducting research. In 
other words, every piece of static information can be synthesized and placed into steps of research, which produce the structure and become dynamic procedure of research. Table 4 presents the framework of VCRC activities from the case. Among which, research seminars and research progress meetings that are conducted with collaborative synchronous mechanism are those times when personal tacit knowledge transform into explicit domain. On the other hand, activities that happen with individual asynchronous mechanism are where tacit personal knowledge transforms into explicit personal knowledge that are publicly shared. Last, activities happen with collaborative asynchronous mechanism such as research paper review, research publication, and thesis, are that explicit personal knowledge that awaits individuals to internalize and transform into personal tacit knowledge.

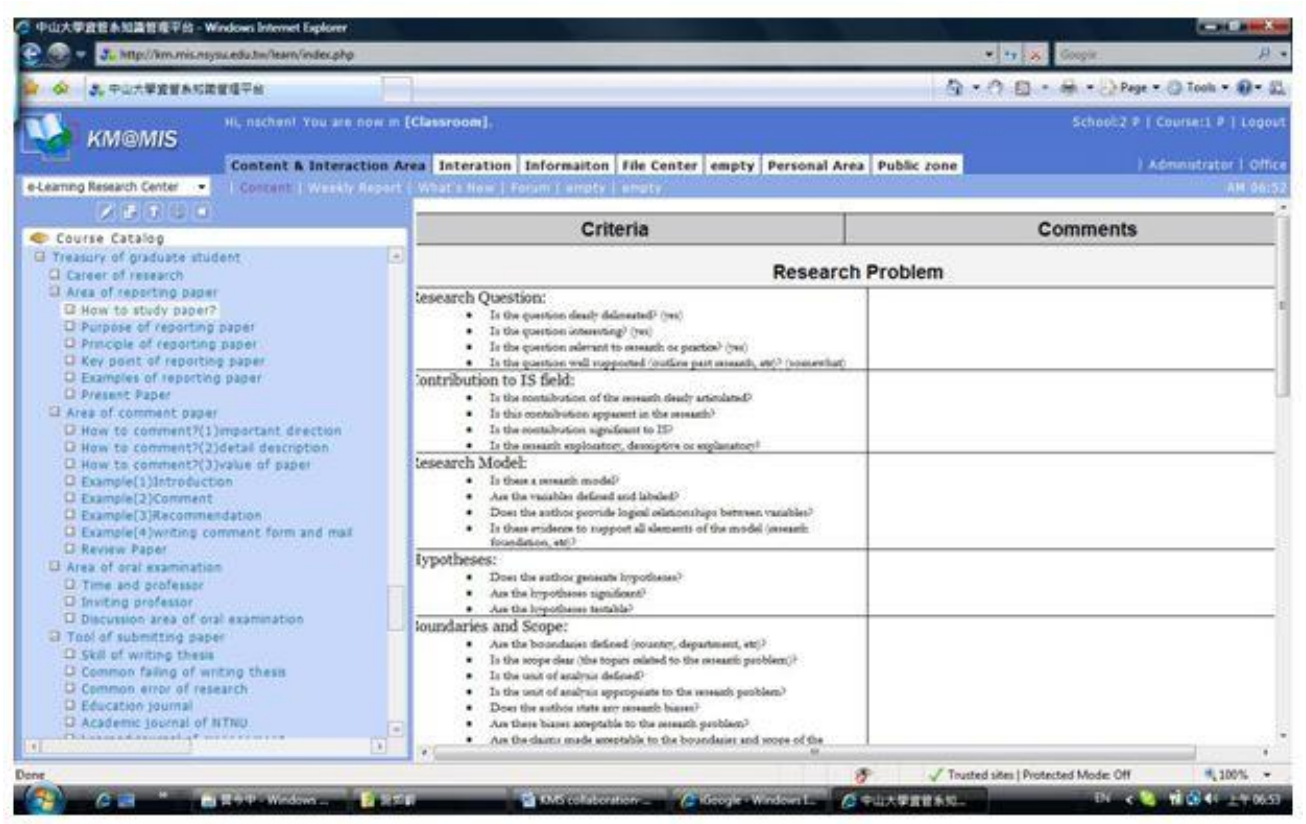

Figure 6. Collaborative knowledge structure

Table 4. A framework of VCRC activities from the case

\begin{tabular}{|l|l|l|}
\hline & Individual & Collaborative \\
\hline Synchronous & Not Applicable. & $\begin{array}{l}\text { Research seminar } \\
\text { Small group meeting } \\
\text { Appointment discussion }\end{array}$ \\
\hline \multirow{3}{*}{ Asynchronous } & $\begin{array}{l}\text { Personal research portfolio area } \\
\text { Research documents } \\
\text { Knowledge construction }\end{array}$ & $\begin{array}{l}\text { Research paper review } \\
\text { Research publication } \\
\text { Thesis }\end{array}$ \\
\hline
\end{tabular}




\subsection{Knowledge Flow of KMS Activities}

The responses of user questionnaire are analyzed with theories for in-depth understanding of the user experience of KMS, and illustrated in the following sections.

The following section is the analysis of user experience and the knowledge transformation process based on Nonaka's Model (Figure 7). It discusses about how students are using KMS to assist the progress of their research. They normally start with talking to group members (socialization) to get new information and to exchange ideas; then they write their comments on public forum (externalization) to generate deeper thinking on issues. Followed, the KMS manager extracts important information to be collected into public knowledge area (combination); and last, individuals digest such external information and reflect upon it (internalization).

Analysis of Knowledge Transformation based on Nonaka's Model

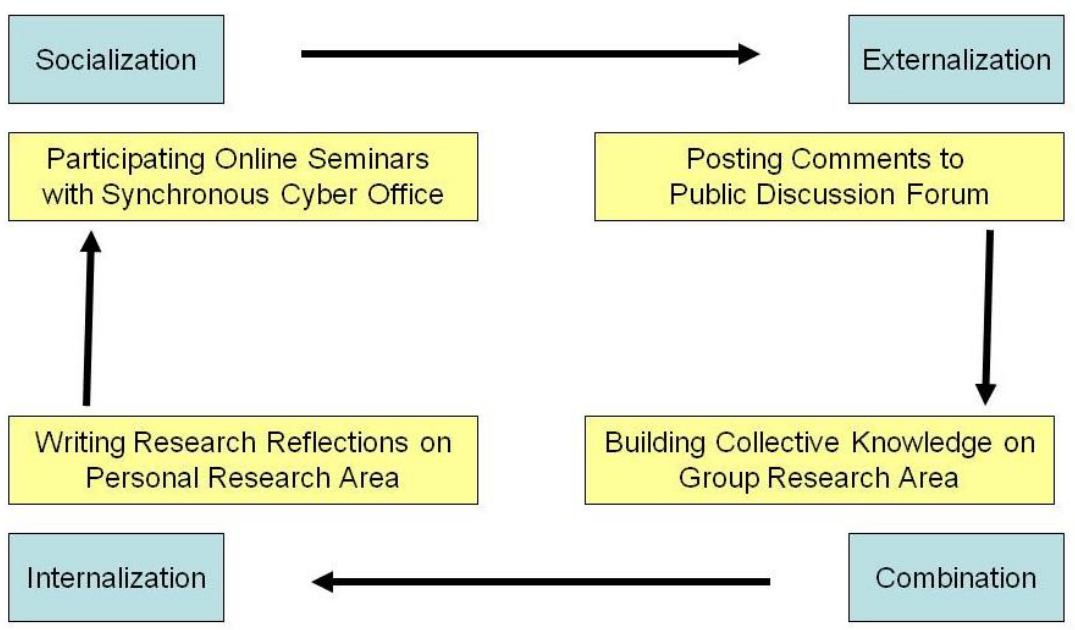

Figure 7. Analysis of Knowledge Transformation based on Nonaka's Model

\section{Knowledge Flow of KMS Activities}

This section presents the analysis results of the question concerning the benefits of KMS to learning and research. Individual research notes the students do in the KMS can be seen as learning portfolio. As students create more and more these portfolios, that is, post notes to the system, they actually create a learning diary (Nückles, Schwonke, Berthold, \& Renkl, 2004). Student E and H both said, although they have computers to use at home, lab, and laptop respectively, KMS offers a nice central permanent platform to load research documents so that the access is easy and seamless.

This approach aims at stimulating a deeper thinking to learning content. According to Bereiter (2002), thinking and elaborating on own activities and what has been read will result in better understanding, and eventually learning, as people learn 
from what they process. Thus, Student D said: "By writing these notes, we have to think more carefully about what are learned or achieved." The fact that students are able to reflect their research process and decisions is important. As Williams and Jacobs (2004) mentioned, blogging forces a student to confront their own opinions and contemplate how their views might be interpreted and reflected upon by others. Therefore, the group member posting to the research areas must think carefully how to share knowledge and opinions in order it to be understandable by others.

Producing a learning diary stimulates the application of elaboration strategies, that is, the construction of external links that relate the new material to the learner's prior knowledge (Nückles et al, 2004). In the interviews several students mentioned the fact that they are able to trace back what they have done, and can use the system to find something they have forgotten. Student B: "KM can help me to record my thoughts. When I forget something, I can go to the forum and see it." Student E, F, I, J, K added that with the personal documents, not only one can trace his or her own progress but also can observe others' progress to avoid repeated mistakes.

By making all these records about their research progress, students give the teacher another perspective on the student's progress (Woodward, 1998). It helps students to sustain retention of the learning material. At the same time, supervisor can easily follow students' documents on regular basis, and monitor the process and progress of students. Obstacles and difficulties students face can be detected so the supervisor can respond and provide assistance immediately. Meanwhile, with shared reviews, one can also get peer support when facing obstacles.

\section{Building Collective Knowledge}

This section presents the analysis results of the question answering what knowledge are worth collecting as group assets. From the questionnaire results, most members think that research experience is the most worthwhile to be shared; that include the general information of the team research focus, the reflections and comments to others' researches, as well as the ideas carried out from the discussion with advisors. Also, Student F mentioned that how to establish, operate, and manage a KMS is also precious information and experience to be shared so that the virtual research community can be carried on. Student K wished that more personal documents such as advisor's comments and private meeting minutes can be elicited to share with others so that everybody can learn from other people's personal experiences.

There are two types of asynchronous collaborative tasks: task based collaboration and common interest based collaboration. The earlier is usually related to editing or reviewing a common document. The later is totally volunteered collaboration, where individual students share their ideas about other students' research. This exists in some extent. Student C said: "I'm happier when someone posts to my area; however there is too small amount of these actions." On top of their own elaborations of knowledge, the group members collect all the data they think is important to their research area. This includes for example scientific articles, their own presentations and so on. By doing this, the group members are actually producing a portfolio (Woodward, 1998).

All the synchronous collaborative tasks are carried out with the synchronous cyber office. The synchronous cyber office allows users to see video of each other simultaneously, discuss and share a document online. The advantages of this approach are obvious. The group members do not need to gather to a meeting room, but can 
conduct the meeting wherever they happen to be. There is no need to set up other advanced technological equipment. Computers with web-cameras, speakers and microphones are sufficient to initiate the online meeting. Attendants of the meeting have clear view to the data presented. Furthermore the system automatically monitors and records the synchronous activities as multimedia files and thus can be accessed later for reference. This is the function students are most appreciated about. For example, student B said: "synchronous cyber office is useful because it records the meeting. If I forget something, I can play the recording later." The recordings of the seminars and meetings are all stored to the KM system. This eventually builds up a library of important knowledge.

Meanwhile, students are able to draw on the electronic whiteboard when needed. It is also possible to modify power point presentation online, which is something difficult to do in the physical meetings. The ability to draw and write on the shared whiteboard can provide a medium to introduce conversational props (Brinck \& Gomez, 1992). These provide the collaborators with focus for the discussion. Thus, this feature substitutes the possibility to point things from the screen or whiteboard in face-to-face meetings and gives the collaborators back some of the awareness (Gutwin \& Greenberg, 2002). Unfortunately, physical interactions as well as eye contact are often missing in the online environment. One of the students mentioned that while having a meeting using synchronous cyber office the feeling of presence is lost. Student D said: "While using the synchronous cyber office, I miss eye contact."

On the other hand, instant feedback and fair opportunity of presentation during the idea generation and problem solving are important criteria. When it is conducted online, users do not need to wait for their turn (Prante, Magerkurth, \& Streitz, 2002). With synchronous cyber office, the collaborators can post their opinions and ideas whenever they feel appropriate without interrupting others. This feature transforms made the synchronicity more realized than the traditional meeting.

\section{Maintaining Virtual Community}

This section presents the analysis results of the question concerning the maintenance of the virtual community. Social knowledge is to build on existing knowledge each individual previously acquired and accumulated. The students see the KMS as a place to share and get support. KMS scaffolds the interaction between peers, and accelerates transformation of the individual work towards collaborative content and knowledge building. Student A: "(by using the KM system) you can learn from others." Student B: "I can see other students' research. We are able to understand research of each other." Student A said: "We can post what we want to share and to gain support from senior students." Student C said: "Emotional support, encouragement of other students and peer support are important." It shows how KMS gives the group better possibility to support its members.

From the questionnaire, students express that the criteria of a successful virtual community include a good and encouraging leader, a nice role model, a clear orientation of the system to new users, active member participation, stable system, and friendly interaction atmosphere including scheduling off-line community activities. Student E, F, $\mathrm{H}, \mathrm{I}, \mathrm{J}$ think that leader is an important criteria to a good virtual research community. The role is not only to maintain the online atmosphere but also to encourage and supervise the interaction between members. Also, clear community rules can help to organize and manage the dynamics of the group, at the same time, to regulate the progress of group 
activities. This can initiate a good culture of use which can help members to carry the tradition on. With dynamic atmosphere, individuals are more willing to participate in the online activities so that positive communication cycle would be generated. Other than that, almost everyone think that official or unofficial offline activities can help to strengthen the unity of a virtual research community.

\section{Sketching New Functions}

This section presents the analysis results of the question regarding the proposed new functions to the current KMS in this case study. One problem related to the massive amount of data is finding the relevant information from the system. Documents can only be searched by file name, creation date, and author. Student A said: "Title of a posting is made by its author. I cannot know what is behind it if I do not click the topic and read it. It is hard to find relevant data this way." It is insufficient for people to find relevant information. Student A said: "In individual research area there is too many data. I cannot know what it includes. It takes too much time to read all the nodes and it is not convenient." And student B said: "KM stores lots of data but I do not use it very much. I feel it stores too much and I do not know how to find relevant data." Unless the users are familiar with other people's work so they can find relevant sources (student B).

It might be good if the group members would be able to organize their data according to categories. This could be achieved by the postings with appropriate keywords. This could also be eased with the possibility to write a brief description about each meeting, and use of proper tagging system to accelerate the searching process. This approach would make accessible and would also force the group members to think more about what they have written or what they are about to post

Actually, students are using sort of tags in their posts even though the system does not provide this mechanism: Student A: "I create tags to the titles of the postings and these help me to organize my information." Common categories that are used are, such as paper, progress and class notes, should be keywords for tags. Tags associated with a particular item are a representation of how a learner has activated related knowledge in his/her mind and associated it with the item (Yew, Gibson, \& Teasley, 2006). Student E, F, H, I, J all proposed that message tag can be added to the asynchronous collaborative discussion board so that the search of information can be easier and the information reuse rate can be raised. Or else, to replace it with keyword search mechanism can solve the problem as well. The tagging could be expanded to social tagging where each member of the research group could tag any content in the system. Tagging has potential to improve search and personal organization and to introduce new modalities for social communication (Marlow, Naaman, Boyd, \& Davis, 2006). A good example of tagging for research purposes is the CiteULike website (www.citeulike.org). In short, by utilizing tagging students could add more extracted knowledge to their posts and thus could facilitate the knowledge searching process of peers and the reuse of existing knowledge.

In order to make data accessible for all the students, there is a need for further processing of the data, a value added knowledge building mechanism. In the lab this is solved by instructing all the new students to go through the knowledge structure map of the lab and to familiarize themselves with the existing data. With this approach these new students will have good general understanding of what is happening in the lab, what has been done and especially, how it has been done. As one of the main benefits of using these kinds of system is that the knowledge that is gradually accumulated to the system, it might be seen unbeneficial for the users at the beginning. This is why it must be carefully 
explained the concept of the tool and to create common rules and instructions how and when the system should be used. Note taking mechanism can be added to support online documentation. Other than that, Student G suggested to create an online helper feature to increase the human touch of KMS.

The collaborators are not able to edit or modify the documents uploaded to the synchronous cyber office. This is due to the fact that the documents are uploaded as images. Student B said: "In synchronous cyber office the file, e.g. PowerPoint, is just an image. I cannot edit the file if I would like to during the meeting. It would be good if I could change for example a word in my file during the seminar."

On the other hand, due to the shifting goals and interests of the community across the long time span, information stored on the KMS need to be selected and reorganized to have a more accessible structure. Besides simple interface and supportive function, there is a need for value-added collaborative knowledge building mechanisms. Users suggest that reference management tool similar to Bibtext, EndNote, or RefWork would enhance the sharing of documents. Others suggest adding in a version management tool so that when authors want to edit the same piece of text at the same time to enhance group writing efficiency which is similar to what Lee, Chang, and Narayanan (1998) proposed in their research. And when writing proceed synchronously (Kim \& Eklundh, 2001), other tools like GoogleDocs can be useful.

\section{Conclusions}

From the research we found that three areas in the KMS are essential for VCRC, namely interaction area, personal research portfolio area and accumulated knowledge area. The interaction area is for informal communication and information sharing. Personal research portfolio area is for individuals to document the research progress with related documents. The accumulated area is for storing data that the group think are important for future use. With these three areas, individual knowledge construction process can be transformed into collaborative knowledge building. In the research, we see the cycle of knowledge use going through stages from creation, distribution, selection, collection, to reception. In the process of using and re-using knowledge, the individual and collaborative learning activities have helped to create organizational memories. We witness how tacit knowledge transforms into explicit knowledge.

Traditionally, students would present their research works when finished, but now with KMS students are able to share them as they proceed. This research mainly contributes to three perspectives. First is the contribution to theory construction. From the research we found that with the support of synchronous and asynchronous information technology embedded in one system, it can mainly enhance the conventional research training from constructive to accumulative. Second is the contribution to managing virtual community. While the research training task transforms from individual to collaborative, it gives the research working team more efficient way to train novice researchers. While the research training practices transform from the real world to the virtual world, all the training interactions are done through group understanding. Third is the contribution to building effective knowledge management system. Roth and Roychoudhury (1992) mentioned that knowledge is constructed with social consensus. The KMS provides accessibility to reconstruct group knowledge system and share practical experiences on the system to accumulate knowledge. It reveals the value of the collaboration on construction (Resnick, 1996). 
For future developments of the KMS include the social tagging and note taking mechanisms. The researchers in the lab are also putting efforts in adding modules such as online reference database and online editing tool. On the other hand, as the growing concept of the knowledge management, the groups are trying to maintain the community of practice with leadership, peer support, and individual endeavors.

However, there are also challenges to explore other related issues in the future. Research may include the analysis of knowledge types, categories, and their relationship between each other so that researchers can develop better structures of KMS and corresponding strategies of maintaining it. A longitudinal study like this can also help to see the development of technology and its value to learning and research.

\section{Acknowledgments}

This research was supported the National Science Council in Taiwan under project numbers NSC 96-2520-S-024 -005, NSC 97-2511-S-110-005-MY3, and NSC 98-2511-S024-006-MY2.

\section{References}

1 Bereiter, C. (2002). Education and Mind in the Knowledge Age. Mahwah, NJ: Lawrence Erlbaum Associates.

2 Brinck, T. \& Gomez, L. M. (1992). A Collaborative Medium for the Support of Conversational Props. Proceedings of the 1992 ACM Conference on ComputerSupported Cooperative Work, CSCW'92. ACM, 171-178.

3 Davenport, T. \& Prusak, L. (1998). Working Knowledge, What Organizations Manage What They Know. Boston, MA: Harvard Business School Press.

4 Diaper D. \& Sanger C. (2006). Tasks for and Tasks in Human-Computer Interaction. Interacting with Computers, 18(1), 117-138.

5 Gover, V. \& Davenport, T. H. (2001). General Perspectives on Knowledge Management: Fostering a Research Agenda. Journal of Management Information Systems, 18(1), 5-21.

6 Gupta, B. M. \& Karisiddappa, C. R. (1998). Collaboration in Theoretical Population Genetics Specialty. Scientometrics, 42(3), 349-376.

7 Gutwin, C. \& Greenberg, S. (2002). A Descriptive Framework of Workspace Awareness for Real-Time Groupware. Computer Supported Cooperative Work (CSCW), 11(3/4), 411-446.

8 Hoadley, C. M. \& Killner, P. G. (2005). Using Technology to Transform Communities of Practice into Knowledge-Building Communities. SIGGRO Bulletin, 25(1), 31-39.

9 Jackson, C. (2000). Process to Product: creating tools for knowledge management. In Y. Malhotra (ed.), Knowledge Management and Business Model Innovation. pp. 402-412. Hershey, PA: Idea Group Publishing.

10 Karger, D. R. \& Quan, D. (2005). What would it mean to blog on the semantic web? Web Semantics: Science, Services and Agents on the World Wide Web, 147-157.

11 Kim, H. C. \& Eklundh, K. S. (2001). Reviewing Practices in Collaborative Writing. Computer Supported Cooperative Work, 10(2), 247-259. 
12 Krogh, G. V. (1998). Care in knowledge creation. California Management Review, 40(3), 133-153.

13 Kuo, Y.-H. \& Chu, C.-H. (2007). Effects of Information Presentation Styles on Information Reuse Based on Knowledge Management system. Proceedings of the 2007 Conference on Technology Enhanced Learning, TELearn 2007.

14 Lee, B. G., Chang, K. H., \& Narayanan, N. H. (1998). An Integrated Approach to Version Control Management in Computer Supported Collaborative Writing. Proceedings of the 36th Annual Southeast Regional Conference ACM-SE 36. ACM, 34-43.

15 Marlow, C., Naaman, M., Boyd, D., \& Davis, M. (2006). HT06, Tagging Paper, Taxonomy, Flickr, Academic Article, to Read. Proceedings of the Seventeenth Conference on Hypertext and Hypermedia, HYPERTEXT' '06. ACM, 31-40.

16 Nishida, T. (1999). Facilitating community knowledge evolution by talking virtualized egos. Proceedings of the HCI International '99 (the 8th International Conference on Human-Computer Interaction) on Human-Computer Interaction: Communication, Cooperation, and Application Design, 2, 437-441.

17 Nonaka, I. \& Takeuchi, H. (1995). The Knowledge-Creating Company. New York: Oxford University Press.

18 Nückles, M., Schwonke, R., Berthold, K., \& Renkl, A. (2004). The Use of Public Learning Diaries in Blended Learning. Journal of Educational Media, 29(1), 49-66.

19 Prante, T., Magerkurth, C., \& Streitz, N. (2002). Developing CSCW Tools for Idea Finding: Empirical Results and Implications for Design. Proceedings of the 2002 ACM Conference on Computer Supported Cooperative Work, CSCW '02. ACM, 106-115.

20 Resnick, M. (1996). Distributed Constructionism. Proceedings of the International Conference on the Learning Science. 280-284.

21 Rosenberg, M. J. (2001). E-learning: strategies for delivering knowledge in the digital age. NY: McGraw Hill Publishing.

22 Roth, W.-M. \& Roychooudhury, A. (1992). The Social Construction of Scientific Concepts or the Concept Map as Conscription Device and Tool for Social Thinking in High School Science. Science Education, 76(5), 531-557.

23 Su, H., Zhang, H., \& Hashemi, R. (2007). Distributed, Integrated, and Collaborative Research Environment (DiCore): An Architectural Design. Software Engineering, Artificial Intelligence, Networking, and Parallel/Distributed Computing, 2007 (SNPD 2007), Eighth ACIS International Conference, 21-26.

24 Wagner, C., \& Bolloju, N. (2005). Supporting knowledge management in organizations with conversational technologies: Discussion forums, weblogs, and wikis. Journal of Database Management, 16 (2), 1-8.

25 Wang, F., Rabsch, C., Kling, P., Peiya, L., \& Pearson, J. (2007). Web-Based Collaborative Information Integration for Scientific Research Data Engineering. (ICDE 2007), IEEE 23rd International Conference, 1232-1241.

26 Wasserman, S. \& Faust, K. (1994). Social Network Analysis: Methods and Applications. Cambridge: Cambridge University Press.

27 Williams, J. B. \& Jacobs, J. (2004). Exploring the Use of Blogs as Learning Spaces in the Higher Education Sector. Australasian Journal of Educational Technology, 20(2), 232-247. 
28 Woodward, H. (1998). Reflective Journals and Portfolios: learning through assessment. Assessment \& Evaluation in Higher Education, 23(4), 415-423.

29 Yew, J., Gibson, F., \& Teasley, S. (2006) Learning by Tagging: Group Knowledge Formation in a Self-Organizing Learning Community. Proceedings of the 7th international Conference on Learning Sciences, International Conference on Learning Sciences, 1010-1011.

30 Zack, M. H. (1999). Managing codified knowledge. Sloan Management Review, 40(4), Summer: 45-58. 